\title{
Talidomida no Brasil: vigilância com responsabilidade compartilhada?
}

\author{
Thalidomide in Brazil: \\ monitoring with shared responsibility?
}

Maria Auxiliadora Oliveira 1

Jorge Antôni o Zepeda Bermudez 1

Arthur Custódio Morei ra de Souza 2

\footnotetext{
1 Núcleo de Assistência Farmacêutica, Escola Nacional de Saúde Pública. Rua Leopoldo Bulhões 1480/617, Rio de Janeiro, RJ 21041-210, Brasil.

2 Movimento de Reintegração das Pessoas Atingi das pela Hanseníase (Morhan).

Rua do Matoso 6, grupo 205, Rio de Janeiro, RJ 20270-130, Brasil.
}

Abstract This paper discusses issues related to the regulation and rational use of thalidomide in Brazil, by means of a historical approach comprising three different stages. The first part is a historical review of the controversial drug since it was first synthesized, then marketed and subsequently banned during the 1950s and 60s, until the present, when an apparently irreversible process of rehabilitating the drug is under way. Brazilian experience with the use of thalidomide is described, emphasizing legal, political, and institutional work led by two social movements, the Brazilian Association of People with Thalidomide Syndrome (ABPST) and the Movement for Reintegration of People with Hansen's Di sease (Morhan). The article describes the results and analyzes an active search of new cases in what is a second generation of thalidomide syndrome in Brazil. Finally, based on clinical and scientific evidence of thalidomide's therapeutic efficacy, the growth of social movements struggling both for and against authorization of the drug, and a restrictive regulation proposed by the Ministry of Health, the article discusses the implementation of policies for the regulation and rational use of thalidomidein Brazil.

Key words Thalidomide; Drug Regulation; Drug Legislation

Resumo Estetrabal ho analisa questões relacionadas ao processo de regulação e uso racional da talidomi da no Brasil, mediante abordagem histórica, que percorre três momentos distintos. O primei ro segmento é composto por um rastreamento dos caminhos percorridos por esse polêmico medicamento, desdea fase inicial de sua síntese, mercadização e banimento, ocorri dos na dé cada de 50 e início dos anos 60, até os dias atuais, quando se encontra em curso um processo, aparentemente irreversível, de reabilitação da droga. Em segui da, relata-se a experiência brasilei ra com o uso da talidomida, enfatizando o trabalho desenvol vido pela ABPST e pelo Morhan nos campos jurídico, políti co e institucional. São apresentados e analisados os resultados de uma pesquisa de busca ativa dos casos, que compõem a chamada segunda geração dos portadores da síndrome da talidomida no Brasil. Finalizando, à luz das evidências clíni cas e científicas da eficácia terapêutica da talidomida, do crescimento de movimentos sociais a favor e contra a li beração do uso da mesma e da proposta de regulamentação restritiva do Ministério da Saúde, discutem-se aspectos relacionados à implementação da política de regulação e uso racional da talidomida no Brasil.

Palavras-chave Talidomida; Regulação de Medicamentos; Legi slação de Medicamentos 


\section{Introdução}

Em setembro de 1997, foi anunciado na imprensa internacional (McLean, 1997; Rutter, 1997) que a agência regulatória norte-americana Food and Drug Administration (FDA) planejava aprovar a reintrodução da talidomida no mercado americano. De acordo com as palavras de Harry Schwartz, jornalista do The New York Times: "This was as astoni shing as would have been the reinstatement, after the American revolution by President GeorgeWashington, of the traitor and British spy, Benedict Arnold, to all his former military rank, honours and privileges" (Schwartz, 1997:30).

Tamanha perplexidade se justifica porque há quarenta anos aconteceu uma das mais terríveis tragédias da história da farmacoterapia: o desastre da talidomida. Entre 1958 e 1962, foi observado, principalmente na Alemanha e Inglaterra, o nascimento de milhares de crianças que apresentavam graves deformidades congênitas, caracterizadas pelo encurtamento dos ossos longos dos membros superiores e/ ou inferiores, com ausência total ou parcial das mãos, pés e/ ou dos dedos. Em cerca de $25 \%$ dos casos, verificava-se o acometimento simultâneo e assimétrico dos quatro membros, conformando um quadro que se convencionou denominar de focomelia. Lenz, um médico alemão que vinha acompanhando uma série de casos da nova síndrome, estabeleceu, pela primeira vez, a correlação entre o consumo da talidomida por gestantes e o aparecimento das malformações congênitas (Mellin \& Katzenstein, 1962b).

Diante das fortes evidências clínico-epidemiológicas e da ampla cobertura dada ao caso pela imprensa, o laboratório farmacêutico ChemieGrunenthal, proprietário da patente da talidomida, determinou a retirada do medicamento do mercado alemão. Foi assim que o mundo tomou ciência de que uma substância comercializada como "completamenteinócua... segura... surpreendentemente segura... atóxica e total mente inofensiva" (Braithwaite, 1984) foi a responsável pelo nascimento de cerca de 10 a 15 mil crianças malformadas, então conhecidas como 'os bebês da talidomida'.

Embora tenham acontecido outras tragédias induzidas pelo uso de medicamentos antes e depois dessa, nenhuma delas atingiu tantas vidas nem teve tamanho impacto sobre os organismos reguladores (D'Arcy \& Griffin, 1994; Abraham, 1995; Mokhiber, 1995a). Adicionalmente, este episódio é considerado como um dos mais importantes condicionantes do interesse atual da farmacologia, enfatizando os conceitos de eficácia, relação benefício-risco e benefício-custo (Capellà \& Laporte, 1989).

Por que ressuscitar um medicamento banido de quase todo o mundo há quatro décadas? Qual é a experiência de países como o Brasil, onde a droga foi reabilitada há mais tempo? Que mecanismos de controle e vigilância precisam ser elaborados e acionados para garantir que um novo desastre não volte a ocorrer? Qual é o papel das instituições oficiais do setor saúde e da sociedade civil organizada nesse processo? Este trabalho se propõe a discutir essas questões, através de uma análise histórica, que percorre três momentos distintos. O primeiro segmento é composto por um rastreamento dos caminhos percorridos por esse polêmico medicamento, desde a fase inicial de sua síntese, mercadização e banimento, ocorridos na década de 50 e início dos anos 60, até os dias atuais, quando se encontra em curso um processo, aparentemente irreversível, de reabilitação da droga.

Em seguida, relata-se a experiência brasileira com o uso da talidomida enfatizando o trabal ho desenvolvido pela Associação Brasileira dos Portadores da Síndrome da Talidomida (ABPST) e pelo Movimento pela Reintegração das Pessoas Atingidas pela Hanseníase (Morhan) nos campos jurídico, político e institucional. São apresentados e analisados os resultados de uma pesquisa de busca ativa dos casos que compõem a chamada segunda geração dos portadores da síndrome da talidomida no Brasil.

Finalizando, à luz das evidências clínicas e científicas da eficácia terapêutica da talidomida, do crescimento de movimentos sociais a favor e contra a liberação do uso da mesma e da regulamentação proposta pelo Ministério da Saúde (Portaria 160/97), são abordados aspectos relacionados com a política de regulação e uso racional da talidomida no Brasil.

Talidomida: da síntese ao banimento mundial

1) Droga maravilhosa e mercadização sem limites

Embora sintetizada pela primeira vez em 1953 nos laboratórios da Ciba, apenas no ano seguinte a empresa alemã Chemie Grunenthal sintetizou a substância tendo como objetivo inicial a sua utilização como anti-histamínico. Estudos realizados em animais falharam em confirmar esse efeito, mas demonstraram as propriedades sedativas e hipnóticas da subs- 
tância. Assim, o principal efeito demonstrado nos estudos realizados pela Grunenthal foi a capacidade da talidomida de provocar um sono profundo e duradouro sem provocar efeitos indesejáveis no dia seguinte (Stirling et al., 1997).

Outra importante característica detectada naquela época foi a alegada baixa toxicidade. A despeito de seu potencial hipnótico ser semeIhante ao dos barbitúricos, a intoxicação aguda pela talidomida era considerada um evento quase impossível. Os experimentos realizados em ratos, cobaias e coelhos não mostraram taxas de letalidade significativas, mesmo utilizando altas doses (Mellin \& Katzenstein, 1962a).

Generalizando para humanos os resultados obtidos em animais de laboratório, a Grunenthal Iançou o medicamento no mercado em outubro de 1957. Indicado inicial mente como sedativo e anunciado pela empresa como "inteiramente atóxico", era consumido sem prescrição médica. O Contergan ${ }^{\circledR}$, primeira marca lançada no mercado, transformou-se rapidamente em um dos medicamentos líderes de vendas na Alemanha.

Tendo como alvo a população em geral, já que o produto era de venda livre, mas sem se descuidar da categoria médica, a Grunenthal promoveu uma ampla campanha publicitária com o slogan "completamente inócuo, completamente seguro", com anúncios programados para cinqüenta publicações médicas de primeira linha, além de duzentas mil cartas para médicos do mundo inteiro e cinqüenta mil farmacêuticos. Assim, como relata Mokhiber, "a tali domida tinha saído do ovo e no fim do primeiro ano as vendas já haviam atingi do noventa mil unidades por mês" (Mokhiber, 1995a: 371).

Segundo Lenz (1988), no período pré-marketing, compreendido entre 1954 e 1957, inúmeros ensai os clíni cos foram realizados com o objetivo de avaliar a eficácia da droga para uma ampla diversidade de situações, como distonia neurovegetativa, tuberculose, influenza, coqueluche, hipertensão, arteriosclerose, hipertireoidismo, afecções gástricas de origem nervosa e problemas hepáticos. A empresa disseminava a idéia de que se tratava de uma droga multipotente e livre de efeitos colaterais.

Em agosto de 1956, a Grunenthal mandou imprimir e distribuir um folheto promocional discriminando uma série de indicações terapêuticas da talidomida, como: irritabilidade, baixa concentração, estado de pânico, ejaculação precoce, tensão pré-menstrual, medo de ser examinado, desordens funcionais do estômago e vesícula biliar, doenças infecciosas fe- bris, depressão leve, ansiedade, hipertireoidismo e tuberculose. Indicado também como antiemético, na Alemanha chegou a ser descrito como o melhor medicamento para ser administrado a gestantes e lactantes (D'Arcy \& Griffin, 1994).

Associações medicamentosas com outros compostos também foram comercializadas pela Grunenthal. Esses produtos eram indicados para resfriados, tosse, cefaléias e asma. Uma das apresentações farmacêuticas sob forma de líquido era usual mente utilizada em hospitais alemães para sedar crianças durante exame eletroencefalográfico (Stirling et al., 1997).

O aumento colossal das vendas teve enorme impacto no balanço financeiro da empresa, de tal sorte que, em 1960, no auge do processo de expansão do mercado, apenas na Alemanha foram vendidas aproximadamente 14 toneladas do produto por ano (Zwingenberger \& Wnendt, 1996). Em nível mundial, cerca de vinte países foram licenciados para produzir e/ ou distribuir a talidomida. Nessa ocasião, 14 empresas eram responsáveis pela produção do medicamento sob 17 diferentes nomes de marca (Mellin \& Katzenstein, 1962a; Stirling et al., 1997). Assim, a comercialização da talidomida rapidamente se difundiu por todos os continentes, incluindo 11 países europeus, sete africanos, 17 asiáticos e 11 nas Américas do Norte e do Sul (Mokhiber, 1995a).

Paral elamente ao crescimento das vendas, começaram a surgir os primei ros relatos médicos sobre reações adversas, incluindo constipação intestinal, tonteiras, sensação de ressaca, perda de memória e polineurites, entre outras. Por seu lado, a Grunenthal minimizava esses relatos, atribuindo-os ao uso de altas doses e por tempo prolongado (Mokhiber, 1995a).

\section{2) Expandindo fronteiras}

Na Grã-Bretanha, o medicamento começou a ser vendido em abril de 1958, através da Distillers Biochemicals Ltd. (DBCL), considerada a gigante empresa de bebidas alcoólicas. Essa empresa viu a talidomida como uma droga maravilhosa, que poderia transformar-se numa alternativa para o uísque: "seas pessoasiam engolir pílulas em lugar de Johnny Walker, a DBCL queria garantir sua partici pação nesse mercado". Uma ampla campanha publicitária foi implementada, ressaltando os efeitos benéficos da talidomida, que poderia substituir os barbitúricos, incriminados de provocar um crescente número de mortes por intoxicação, com a vantagem de ser considerada "absolutamente segura eatóxica” (Mokhiber, 1995a:373). 
Embora fosse praxe da indústria farmacêutica realizar testes para descobrir efeitos colaterais, a DBCL iniciou a comercialização do Distival ${ }^{\circledR}$, nome de marca dado à talidomida na Grã-Bretanha, sem nenhum suporte técnico além de um relatório de uma página fornecido pela Grunenthal (Mokhiber, 1995a).

Preocupada com os lucros, essa empresa ignorou os relatos médicos sobre possíveis efeitos colaterais relacionados ao uso prolongado do produto, dentre os quais ressalta-se a neurite periférica (Mellin \& Katzenstein, 1962a). Dois meses antes do início da comercialização do medicamento na Inglaterra, foram publicados no British Medical Journal os resultados das pesquisas realizadas pela DCBL. De acordo com James Murdoch, um dos pesquisadores envolvidos nos testes, "seria injustificável usar a droga por longos períodos como sedativo ou terapia hi pnótica, dependendo de resultados de estudos mais detal hados sobre seus efeitos de Iongo prazo num número maior de pacientes" (Mokhiber, 1995a:372).

Ignorando essas recomendações, o departamento de vendas promoveu ampla campanha publicitária enfatizando a segurança do Distival ${ }^{\circledR}$, de tal forma que um dos anúncios veiculados pela televisão apresentava uma criança pequena tentando alcançar um vidro do remédio em uma prateleira com medicamentos (Stirling et al., 1997).

Como era esperado, o resultado foi espetacular. Em 1961, a DCBL já tinha atingido o patamar de 64 milhões de pílulas de talidomida vendidas. Empenhada em ampliar mais ainda seu mercado, nesse mesmo ano enviou folheto aos médicos afirmando que: “O Distival ${ }^{\circledR}$ pode ser administrado com segurança para gestantes e mães no processo de aleitamento materno sem quaisquer efeitos adversos tanto para as mães como para os bebês..." (Mokhiber, 1995a:374).

\section{3) Talidomida: droga maldita}

A partir de 1959, inicialmente na Alemanha, começaram os relatos médicos sobre o aumento da incidência de nascimentos de crianças com um tipo peculiar de malformação congênita, caracterizada pelo desenvolvimento defeituoso dos ossos longos dos braços e pernase cujas mãos e pés variavam entre o normal e o rudimentar. A essa síndrome foi dado o nome de focomelia, pela semelhança daquelas crianças com a forma externa das focas (Mellin \& Katzenstein, 1962b; D'Arcy \& Griffin, 1994; Stirling et al., 1997)

Em setembro de 1961, Wiedemann (Mellin \& Katzenstein, 1962b) chamou a atenção para o aumento da incidência de malformações hipoplásticas ou aplásticas das extremidades, tendo levantado a hipótese de associação desses eventos com o uso de al gum novo medicamento. Naquela ocasião, vivia-se a famosa era de ouro da indústria farmacêutica, que colocava anualmente no mercado uma enorme quantidade e variedade de novos produtos (Bermudez, 1995).

Entretanto, foi em novembro de 1961, durante o North Rhein-Westphalia Pediatric Meeting em Dusseldorf, Alemanha, que Lenz, após a apresentação de 34 casos de recém-natos com graves deformidades das extremidades, em pesquisa realizada por Pfeiffer \& Kosenow, levantou publicamente a possibilidade de as anomalias congênitas relatadas terem sido provocadas pelo consumo de talidomida durante a gestação (Mellin \& Katzenstein, 1962b).

Essa hipótese foi reforçada por McBride (1961), estabelecendo a correlação entre o uso da talidomida em gestantes e o desenvolvimento das referidas anormalidades congênitas. Esse pesquisador observou que $20 \%$ das gestantes por ele acompanhadas e que fizeram uso do Distival ${ }^{\circledR}$ como antiemético durante a gravidez, geraram crianças com múltiplas e graves anormalidades, enquanto a incidência geral de anormalidades congênitas observadas anteriormente em seu país era de cerca de 1,5\%.

A essa altura, a tragédia do nascimento de milhares de crianças com graves deformidades já havia ocorrido em todo o mundo, com uma especial concentração na Alemanha Ocidental e na Inglaterra.

Embora a focomelia seja a malformação congênita mais difundida como associada ao uso da talidomida, Mellin \& Katzenstein (1962b) descreveram outras anomalias comprometendo diversos sistemas e órgãos. Como conseqüência, a talidomida foi retirada do mercado pela ChemieGrunenthal em novembro de 1961, pela DBCL em dezembro de 1961, e pela William S. Merrel Company em março de 1962.

Nos Estados Unidos, onde a talidomida não chegou a ser licenciada em razão de exigências sobre segurança impostas por uma funcionária da agência regulatória americana, o Food and Drug Administration (FDA) saiu desse episódio fortalecido, passando a assumir a coordenação de todas as atividades relativas à política de regulação de medicamentos naquele país, a partir da emenda Kefauver-Harris de outubro de 1962 (Kelsey, 1988). Estudos de eficácia de novos e antigos medicamentos foram regulamentados por essa agência, passando a ser exigidos para o registro de fármacos. Adicionalmente, ao FDA foi conferida autonomia para cassar li- 
cenças dadas a medicamentos cuja segurança e eficácia viessem a ser contestadas, passando a ser exigido o cumprimento de um longo e rigoroso processo de comprovação da segurança e eficácia de cada substância candidata a medicamento (Kelsey, 1988; Abraham, 1995).

Vale ressaltar que, naquela ocasião, ainda não estava devidamente esclarecida a correlação entre o consumo dessa substância e os defeitos congênitos citados. Além disso, mesmo os efeitos colaterais já reconhecidos, como a polineurite, eram minimizados ou até omitidos pela empresa alemã (Kelsey, 1988). Os casos de anomalias congênitas registrados nos Estados Unidos causados pelo uso da talidomida ocorreram em conseqüência de ensaios clínico-terapêuticos realizados por cerca de 1.200 médicos, que receberam o medicamento diretamente da empresa, utilizando-o como antiemético em suas pacientes gestantes. Não havia, naquela época, nenhum tipo de controlegovernamental sobre a realização de testes clínicos com medicamentos em território americano (Kelsey, 1988).

A talidomida começou a ser comercializada no Brasil em março de 1958, tendo sido relatados os primeiros casos de malformações a partir de 1960. Apesar de ter sido retirada do mercado na Alemanha e Inglaterra no final de 1961, por total falta de informação quanto aos efeitos adversos já comprovados, o medicamento continuou sendo vendido em nosso país como uma droga "isenta de efeitos colaterais", pelo menos até junho de 1962 (Lenz, 1988). Nesse período (1958-1962), a talidomida foi comercializada em território nacional por diversos laboratórios farmacêuticos, sob diversos nomes de marca.

No período compreendido entre 1962 e 1965, a talidomida foi banida de quase todo o mundo. De acordo com informações obtidas junto à Associação Brasileira dos Portadores da Síndrome da Talidomida (ABPST), esse medicamento só foi de fato retirado do mercado brasileiro em 1965, ou seja, com pelo menos quatro anos de atraso. O número de vítimas ditas de primeira geração é estimado em cerca de trezentos. Segundo Lenz (1988), os casos que ocorreram no período compreendido entre agosto de 1962 e 1965 devem ser considerados como casos evitáveis da síndrome.

A retirada da droga não encerrou a questão, pois existiam milhares de crianças vítimas da talidomida, cujas vidas seriam marcadas por sérias dificuldades e cujos familiares decidiram se organizar para exigir al gum tipo de indenização das empresas produtoras. Esse movimento acabou se disseminando nas várias regiões do mundo.

\section{A hanseníase e a talidomida reabilitada}

Quis o acaso que a droga encontrasse novos caminhos que permitissem sua reabilitação, ainda que parcial. Isto ocorreu a partir de 1965, quando um dermatologista israelense prescreveu o medicamento a um paciente que apresentava hiperatividade psíquica associada a um quadro de grave reação hansênica do tipo II (eritema nodoso ou ENL) (Sheskin, 1965a). No dia seguinte, pôde constatar uma melhora acentuada e rápida do quadro geral do paciente com regressão importante das lesões cutâneas. Este fato foi posteriormente comprovado por diversos estudos realizados, incluindo um ensaio clínico, multicêntrico e duplo-cego coordenado pela Organização Mundial da Saúde (OMS) (Sheskin, 1965b; Iyer et al., 1971; Sheskin \& Sagher, 1975; WHO, 1988; Sampaio et al., 1993; Lockwood, 1996). O tratamento dos casos graves de reação hansênica tipo II (ENL), cuja resposta aos esquemas terapêuticos tradicionais seja insatisfatória, pode ser considerada como a primeira indicação precisa para o uso da talidomida.

Embora fosse conhecida desde o início da década de 60 a capacidade dessa substância de prolongar a vida de transplantes homólogos em animais de laboratório (Hellman et al., 1965), a atividade antiinflamatória e imunomoduladora da talidomida foi efetivamente enfatizada a partir de 1965. Diversas linhas de pesquisa vêm sendo realizadas com o objetivo de esclarecer os vários mecanismos envolvidos na interação dessa substância com as diferentes linhagens de células do sistema imunológico, retículoendotelial e nervoso (Faure et al., 1980; Sampai o et al., 1991; Sampaio et al., 1993; Zwingenberger \&Wnendt, 1996; Tseng et al., 1996; Calderón et al., 1997).

Uma das mais importantes descobertas nesse sentido foi a demonstração da capacidade da talidomida de inibir a produção do fator de necrose tumoral, o TNF- $\alpha$ (Sampaio et al., 1991; Sampaio et al., 1993). Essa inibição parece ser seletiva, ocorrendo em virtude do aumento da degradação do ácido ribonucléico mensageiro do TNF- $\alpha$ sem afetar outras atividades imunomoduladoras (Moreira et al., 1993). Esta citocina tem papel importante nos processos inflamatórios e imunológicos de algumas condições mórbidas graves, como a caquexia, artrite reumatóide, lúpus eritematoso, doença de Crohn e doença do enxerto-contra-hospedeiro (Calderón et al., 1997).

Outra questão mais recente é a sua capacidade de atuação como agente inibidor da replicação do vírus HIV-1. Um estudo realizado 
com monócitos infectados por este vírus, coIhidos do sangue periférico de 17 pacientes com a Síndrome da Imunodeficiência Adquirida (Aids), demonstrou que a talidomida suprimiu in vitro a ativação de HIV-1 latente naquelas células em 16 dos 17 pacientes com Aids (Makonkawkeyoon et al., 1993). Outro estudo mais recente (Moreira et al., 1997) também demonstrou a capacidade de inibição in vitro da replicação do HIV-1 em macrófagos humanos tratados com talidomida ou análogos.

Esses conhecimentos, associados aos resultados promissores obtidos na experimentação clínica da talidomida em algumas enfermidades graves, como a doença do enxerto-contrahospedeiro, o lúpus eritematoso discóide e algumas afecções associadas à Aids, vêm quebrando resistências à reabilitação desse medicamento.

Muitas questões ainda se encontram sem resposta no campo dos mecanismos de ação da talidomida. Os estudos sobre as suas propriedades imunofarmacológicas são promissores, mas ainda se encontram em fase de desenvolvimento (Calderón et al., 1997). Zwingenberger \&Wnendt (1996:202), após extensa revisão da literatura científica sobre esse assunto, concluem dizendo: "no single mechanism has been identified yet which accounts for the clinical activity of thalidomide".

Quanto às indicações clínicas, em que pese a polêmica envolvendo os riscos do uso da talidomida, já existe algum consenso na literatura internacional em torno do tratamento de determinadas situações, como: reação hansênica do tipo II (ENL), prurigo nodular, prurigo actínico, doença enxerto-contra-hospedeiro (GVHD), lúpus eritematoso discóide, aftose recidivante, lesões mucosas da síndrome de Behcet, úlcera idiopática da Aids (origem não infecciosa) e síndrome de caquexia associada à Aids (Vogelsang et al., 1992; Proença, 1995; Reyes-Terán et al., 1996; Tseng et al., 1996; Calderón et al., 1997).

Entretanto, vale ressaltar que, em razão dos efeitos adversos conhecidos, particularmente a teratogenicidade e a neurotoxicidade, ainda existe muita controvérsia em torno do uso desse medicamento. Nesse sentido, seu uso clínico deve ser criteriosamente avaliado e cuidadosamente ponderado no que tange à relação risco-benefício, principalmente em casos de pacientes que apresentem neuropatia prévia e em mulheres em idade fértil (Crawford, 1994; Lockwood, 1996).
Brasil: comercialização da talidomida, a luta judicial e o surgimento de uma segunda geração de portadores da síndrome da talidomida

Conforme discutido anteriormente, a talidomida continuou sendo utilizada no Brasil mesmo após seu banimento em nível mundial. Segundo relato da ABPST: “na prática, a droga não deixou deser consumida indiscriminadamente, em função da desinformação, descontrole na distribui ção, omissão governamental, automedicação e poder econômico dos laboratórios. Com a sua utilização, surge a denominada segunda geração de vítimas da talidomida" (ABPST, 1997). Convencionou-se denominar de segunda geração de vítimas todos os casos que ocorreram após 1965, ocasião em que esse medicamento, apesar de banido no mundo e retirado do mercado brasileiro, começou a ser utilizado exclusivamente para o tratamento da hanseníase.

Em que pese a grande repercussão mundial do caso das crianças da talidomida, somente em 1973, e em atenção a uma solicitação de Ralph Nader, líder norte-americano de defesa do consumidor, iniciou-se no Brasil um inquérito oficial para avaliar o número de vítimas do uso indiscriminado da droga.

Em 1976 deu-se início a uma ação judicial contra os laboratórios e o governo brasileiro (União) exigindo a responsabilização dos mesmos pela tragédia brasileira. A ação se arrastou por muitos anos, sendo um dos principais problemas a extrema dificuldade de se comprovar, passados tantos anos, a relação causal, nesse caso, uso da talidomida durante a gravidez (Maximino \& Scavasin, 1997).

Após intensa campanha que envolveu mobilização da mídia, o governo brasileiro assumiu sua responsabilidade, sancionando a Lei 7.070, de dezembro de 1982, que concede pensão vitalícia, variando de um a quatro salários mínimos, dependendo do grau de dependência resultante da deformidade física.

Com a inflação dos anos 80, os valores das pensões foram rapidamente corroídos chegando aos níveis irrisórios de US\$ 7,00 mensais. Em 1986, mais uma vez foi necessária a mobilização, que culminou com a criação, em 1992, da ABPST, inicialmente com o objetivo de lutar pela revisão dos valores das pensões e pelo direito ao tratamento cirúrgico, ortopédico e reabilitação. Esta se caracteriza, portanto, como a segunda entidade que se constituiu em virtude da luta pelos direitos das pessoas portadoras de malformações atribuídas à talidomida (Maximino \& Scavasin, 1997). 
Os frutos dessa mobilização começaram a ser colhidos a partir de 20 de julho de 1993, quando foi sancionada a Lei 8.685, que dispõe sobre o reajustamento de pensão especial aos deficientes físicos e portadores da síndrome da tal idomida, instituída pela Lei 7.070 de 21/ 12/ 80. Determina essa lei que o valor da pensão não poderá ser inferior a um salário mínimo, vinculando os reajustes aos mesmos índices utilizados pelo Instituto Nacional de Previdência Social (INPS). Garante também prioridade no fornecimento de aparelhos de prótese, órtese e demais instrumentos de auxílio, bem como nas intervenções cirúrgicas e na assistência médica fornecidas pelo Ministério da Saúde, através do Sistema Ú nico de Saúde.

Paralelamente a esse processo de mobilização pela garantia e ampliação dos direitos sociais dos portadores da síndrome da talidomida, o Movimento pela Reintegração das Pessoas Atingidas pela Hanseníase (Morhan) e a ABPST vinham sendo notificados sobre o surgimento de uma segunda geração de casos.

\section{Morhan e ABPST: busca ativa dos casos da segunda geração}

Em 1988, o Jornal do Morhan relatou a descoberta de um portador da síndrome da talidomida, que tinha nascido no interior de São PauIo. Em 1992, com base nessa denúncia e com a iniciativa de uma rede de televisão inglesa (Yorkshire Television) e do Morhan, foi possível, num curto período de dois meses de pesquisa, identificar 21 casos envolvendo pessoas nascidas após 1965.

Em junho de 1993, a imprensa nacional e internacional divulgou resultados dessa primeira etapa da investigação, causando impacto e despertando o interesse, tanto das autoridades do Ministério da Saúde, quanto de entidades privadas e até estrangeiras em financiar um projeto de investigação, que possibilitasse a identificação de um maior contingente de casos em todo o território nacional. Assim, Morhan e ABPST se uniram e partiram para uma busca ativa de novos casos da síndrome da talidomida.

Fez-se um apelo para que todos os núcleos do Morhan investigassem o aparecimento de crianças nascidas após 1965, que possuíssem deficiências físicas compatíveis com a síndrome da talidomida e história de utilização do medicamento. Num primeiro momento, dezenas de portadores de deficiências físicas se apresentaram. Após triagem inicial, foram selecionados 61 casos que apresentavam defor- midades e história clínica compatíveis com a síndrome em questão. A confirmação foi efetuada por meio de uma investigação, que incluiu visitas domiciliares, consulta a laudos médicos e aos registros dos prontuários das unidades onde ocorreram os tratamentos. Alguns casos foram descobertos pela imprensa e outros, por notificação de profissionais de saúde. Informações também foram obtidas mediante consulta aos arquivos da ABPST e do Instituto Nacional de Seguridade Social (INSS).

1) Características gerais dos casos investigados

$\mathrm{Na}$ análise dos dados referentes aos 61 casos da segunda geração de portadores da síndrome da talidomida, pôde-se constatar que não houve diferença na distribuição dos mesmos quanto ao sexo.

Em relação à distribuição geográfica, houve um maior percentual de detecção de casos nos estados da região Sudeste, onde foram identificados 35 casos, correspondendo a 57,4\% do total confirmado. Apenas no Estado do Rio de Janeiro, foram relatados 13 casos (Tabela 1). Podemos atribuir este resultado a uma melhor estruturação dos núcleos do Mohran-RJ e do sistema oficial de notificação de doenças, além das facilidades de transporte e comunicação.

A distribuição dos casos segundo ano de nascimento mostrou um aumento constante e

Tabela 1

Distribuição dos casos de portadores da síndrome da talidomida segundo origem, por unidade federada. Brasil, 1994.

\begin{tabular}{lc}
\hline Unidade Federada & Freqüência \\
\hline Amazonas & 1 \\
Pará & 2 \\
Maranhão & 2 \\
Ceará & 1 \\
Pernambuco & 2 \\
Bahia & 3 \\
Minas Gerais & 6 \\
Rio de J aneiro & 13 \\
São Paulo & 9 \\
Paraná & 4 \\
Santa Catarina & 1 \\
Rio Grande do Sul & 2 \\
Mato Grosso do Sul & 1 \\
Sem informação & 14 \\
Total & 61
\end{tabular}


significativo do número de casos a cada período de cinco anos até 1984, com declínio posterior. Dentre os 61 casos identificados, 19 nasceram no período compreendido entre 19801984 , correspondendo a 31,1\% do total de casos detectados (Tabela 2).

2) Como e por que foi indicada a talidomida?

Em uma amostra não aleatória de 44 domicílios, foram realizadas entrevistas aplicando-se um questionário semi-estruturado, denominado Ficha de Cadastro de Crianças Vítimas de Talidomida, o qual é composto de três partes.

Na primeira, foram coletados dados gerais referentes à identificação do indivíduo, do tipo: nome, data de nascimento, endereço, filiação, número de irmãos, renda familiar per capita, nome e endereço completo da pessoa entrevistada; foram levantados também dados sobre integração desses indivíduos à sociedade, como atividades de estudo e trabalho, profissão e se recebem a pensão determinada pela Lei 7.070 .

Na segunda parte do questionário - motivo de ter tomado a talidomida -, foram investigadas as características do uso e da prescrição do medicamento: se houve prescrição médica e, nesse caso, se foi dada orientação quanto aos efeitos teratogênicos; se foi um caso de automedicação para hanseníase ou para outra doença; se na ocasião da prescrição e do uso a muIher estava grávida.

A terceira parte do questionário foi voltada para uma descrição das deficiências apresentadas e das necessidades de cada um dos casos no que se refere a intervenções médicas, próteses, adaptações e até apoio financeiro.

A sistematização e análise dos dados dessas 44 entrevistas permitiu uma avaliação da racio-

Tabela 2

Distribuição dos casos da segunda geração de portadores de síndrome da talidomida segundo período de nascimento. Brasil, 1994.

\begin{tabular}{lcc}
\hline Ano de nascimento & Freqüência & Percentual \\
\hline $65-69$ & 3 & 4,9 \\
$70-74$ & 5 & 13,1 \\
$75-79$ & 12 & 19,7 \\
$80-84$ & 19 & 31,1 \\
$85-89$ & 14 & 23,0 \\
$90-94$ & 8 & 13,1 \\
Total & 61 & 100,0 \\
\hline
\end{tabular}

nalidade e qualidade da prescrição e das condições de uso do medicamento pelas mães das crianças afetadas pela síndrome. Dentre os motivos alegados para o uso da talidomida, a reação hansênica ocupou o primeiro lugar, com um percentual de $72,7 \%$. Os $27,3 \%$ restantes utilizaram o medicamento sem prescrição médica e por outros motivos não especificados.

Quando observamos os dados referentes às características da prescrição (Tabela 3), a situação é preocupante, pois, embora na maioria dos casos o medicamento tenha sido prescrito por médico $(68,1 \%)$, o percentual de automedicação de $31,8 \%$ foi alto, principalmente se considerarmos a gravidade dos efeitos adversos da talidomida, assim como as dificuldades no acesso da população a esse medicamento, distribuído exclusivamente na rede pública de serviços de saúde. Dentre aqueles que não eram portadores de hanseníase, o acesso ao medicamento se deu por o mesmo estar sendo utilizado por parentes ou pessoas próximas.

Outra questão alarmante foi a constatação da falta de orientação das pacientes, ou meIhor, das mulheres em idade fértil, quanto ao efeito teratogênico da talidomida. Quatro dessas 44 mulheres entrevistadas estavam grávidas no momento da prescrição!

No que se refere aos tipos de malformações apresentadas, houve um maior percentual de deformidade nos membros superiores $(56,8 \%)$, seguido de focomelia, que foi descrita em 34,1\% dos casos ( Tabela 4). Esses resultados são semelhantes aos dos relatos sobre prevalência de malformações causadas pela talidomida feitos na década de 60 (Mellin \& Katzenstein, 1962a, 1962b; Lenz, 1988).

\section{Brasil: anos 90 e a pactuação de medidas restritivas}

Uma das conseqüências da divulgação dos resultados dessa pesquisa no Brasil, foi a proibição da prescrição da talidomida para mulheres em idade fértil, em todo o território nacional, que se deu por intermédio da Portaria 63 da Secretaria de Vigilância Sanitária do Ministério da Saúde, publicada no Diário Oficial da União em 06 de julho de 1994.

Esta proibição atendia à reivindicação das entidades representativas dos portadores da síndrome da talidomida, que proclamam um maior rigor na vigilância da produção, comercialização, prescrição, dispensação e uso do referido medicamento (Scavasin \& Maximino, 1997). Por outro lado, enquanto medida de caráter restritivo, gerou profunda insatisfação em 
al guns grupos sociais, dentre eles os médicos, que se sentiram tolhidos na sua liberdade de prescrever o medicamento para seus pacientes, e as mulheres acometidas por doenças graves, que se viram discriminadas no seu direito de acesso à talidomida.

Cabe ressaltar que entidades feministas manifestaram publicamente suas críticas à medida, considerada discriminatória de gênero. Há relato de medidas judiciais originadas por pacientes do sexo feminino, que obtiveram liminares autorizando o direito ao uso da talidomi$\mathrm{da}$, por se tratar de medicamento com indicação médica considerada pertinente.

Este conflito de interesses criou um ambiente propício para o desenvolvimento de um processo que podemos denominar de renegociação ou pactuação das medidas existentes sobre o manejo da droga, englobando todo o ciclo que vai da produção ao uso. Neste contexto, o Ministério da Saúde propôs a constituição de dois grupos de trabalho para revisar e atualizar a norma técnica que regulamentava o uso da talidomida no Brasil.

Foi dessa forma que, no período compreendido entre os últimos meses de 1996 e o primeiro trimestre de 1997, foi estabelecido um consenso sobre os diversos aspectos relacionados com o uso da talidomida. Ao se colocarem as diferentes especialidades médicas em grupos de trabalho, os programas que potencialmente utilizariam o produto, em especial os de controle de hanseniase e Aids, junto com entidades da sociedade civil organizada, houve a oportunidade de se debater a necessidade de prosseguir com medidas de caráter restritivo, ao mesmo tempo abrindo a possibilidade de poder ser utilizada a talidomida naqueles casos em que houvesse indicação clínica precisa, esgotados outros meios terapêuticos e comprometendo o prescritor com uma série de ações complementares objetivando impossibilitar seu uso em gestantes.

O resultado desse processo gerou a Portaria 160/ 97 da Secretaria de Vigilância Sanitária, publicada no Diário Oficial da União de 28 de abril de 1997, que limita a produção de talidomida no Brasil aos laboratórios oficiais de produção, podendo o setor privado ser autorizado pelo Ministério da Saúde em caso necessário e em caráter de complementaridade. Ao mesmo tempo, sua comercialização foi proibida e sua distribuição manteve-se restrita aos serviços públicos de referência naqueles programas implementados pelas três esferas que compõem o Sistema Único de Saúde.

Foi mantida a proibição para uso em muIheres em idade fértil, assim compreendido da
Tabela 3

Distribuição dos casos da segunda geração de portadores da síndrome da talidomida de acordo com as características da prescrição da droga. Brasil, 1994.

\begin{tabular}{lcc}
\hline & Freqüência & Percentual \\
\hline Prescrição médica com orientação* & 2 & 4,5 \\
Prescrição médica sem orientação & 28 & 63,6 \\
Subtotal ** & 30 & 68,1 \\
Automedicação p/ hanseníase & 2 & 4,5 \\
Automedicação s/ hanseníase & 12 & 27,3 \\
Subtotal & 14 & 31,8 \\
Total & 44 & 100,0 \\
\hline
\end{tabular}

* O rientação com relação ao efeito teratogênico.

** Este grupo inclui quatro pacientes que apresentaram reação hansênica

e que se encontravam grávidas no momento da prescrição.

Tabela 4

Distribuição dos casos identificados da segunda geração de portadores da síndrome da talidomida segundo tipo de deficiência. Brasil, 1994.

\begin{tabular}{lcc}
\hline Tipo de deficiência & Freqüência & Percentual \\
\hline Extremidades dos membros superiores & 25 & 56,8 \\
Focomelia & 15 & 34,1 \\
Extremidades do membros inferiores & 2 & 4,5 \\
Atrofia total das pernas & 2 & 4,5 \\
Redução da audição & - & - \\
Redução visual ou cegueira & - & - \\
Ó rgãos internos & - & - \\
Outros & - & - \\
Total de entrevistados & 44 & 100,0 \\
\hline
\end{tabular}

menarca à menopausa. Casos excepcionais de indicação da talidomida, esgotados outros recursos terapêuticos e dentro das condições clínicas aprovadas, devem ser encaminhados de maneira excepcional, com justificativa fundamentada e com a segurança de utilização de medidas contraceptivas, para tratamento em unidades de referência previamente cadastradas pelas secretarias estaduais ou municipais de saúde.

Finalmente, a Portaria mencionada limita as indicações da talidomida às seguintes condições clínicas, no âmbito de programas oficiais:

a) hanseníase (reação hansênica tipo eritema nodoso ou tipo II);

b) DST/Aids (úlceras aftosas idiopáticas nos pacientes portadores de HIV/Aids); 
c) doenças crônico-degenerativas (lúpus eritematoso, doença enxerto-versus-hospedeiro).

\section{Considerações finais}

O processo de reabilitação iniciado em 1965 se consolida nos anos 90, incorporando um forte aliado: o movimento dos ativistas da Aids (PWA, 1995; Project Inform, 1996a, 1996b, 1997; Cadernos pela VIDDA, 1997). Nos últimos dez anos, em decorrência dos avanços no conhecimento científico sobre a ação da talidomida como agente modulador da resposta imune, bem como de sua capacidade de inibir a resposta inflamatória e a replicação do vírus HIV1 , novas indicações clínicas foram sendo incorporadas, além das situações que a literatura médica já havia consagrado. É inegável que a talidomida representou importante avanço terapêutico para os casos de portadores de HIV/Aids com aftose recidivante ou síndrome de caquexia, assim como, para a doença do enxertocontra-hospedeiro. Esta última acomete pessoas que se submeteram a transplantes de medula e costuma evoluir de forma extremamente grave.

Calderon et al. (1997) levantam uma série de considerações em relação ao uso da talidomida na Aids. Em relação aos benefícios, esses autores ressaltam a capacidade que a talidomida tem de:

- inibir a replicação do HIV-1 e, conseqüentemente, baixar a carga viral;

- diminuir, sem suprimir, a produção do fator de necrose tumoral (TNF- $\alpha$ ), cuja elevação, normal em pacientes HIV/Aids, vem sendo correlacionada tanto com o desenvolvimento das síndromes de caquexia e de choque séptico, quanto com a ativação dos processos de replicação e propagação do HIV-1, assim como com a progressão acelerada da Aids em pacientes co-infectados com HIV-1 e tuberculose;

- estimular a produção in vivo da citoquina IFN- $\gamma$ em pacientes portadores de HIV/Aids, que parece estar relacionada à diminuição da replicação do HIV in vitro;

Como fatores limitantes do uso, além dos efeitos adversos já conhecidos, a neuropatia e a teratogenia, esses autores acrescentam a questão da maior prevalência de reações de hipersensibilidade à talidomida que vem sendo relatada nesses pacientes.

Assim, chegamos a meados dos anos 90 com o cenário caracterizado, do ponto de vista científico, por um crescente volume de resultados promissores de pesquisas clínicas e labo- ratoriais publicadas nos periódicos científicos e na imprensa leiga, principalmente aqueles resultados relacionados aos benefícios do uso da talidomida em pacientes portadores de HIV/ Aids, associado a denúncias de venda não autorizada, incluindo contrabando, manipulação em farmácias, possibilidade de compra do medicamento via internet (PWA, 1995), através dos conhecidos buyers clubs americanos (Rutter, 1997). Estes últimos se constituíram e se fortaleceram como um movimento de desobediência civil, cujo objetivo é disponibilizar clandestinamente medicamentos proibidos nos Estados Unidos (Epstein, 1995).

Desta forma, nos dias atuais, a questão que se coloca não é mais se a talidomida tem indicação terapêutica nesta ou naquela situação, se deve ou não estar acessível para uso em muIheres, mas sim o que pode ser feito para assegurar que a talidomida seja usada com racionalidade e segurança.

Nessa perspectiva, vale ressaltar a responsabilidade indelegável do Estado como guardião dos interesses dos cidadãos, intervindo por intermédio dos mecanismos de regulação fortemente baseados em evidências tecnocientíficas e com o objetivo de garantir a qualidade, segurança e eficácia dos produtos consumidos pela população. O primeiro passo nessa direção já foi dado com o processo de revisão das normas da Secretaria de Vigilância Sanitária e com a edição da Portaria 1 60/ 97.

Uma medida viável e de extrema importância para a promoção do uso racional desse medicamento em nosso país seria a implantação de um sistema nacional de farmacovigilância da talidomida (Biriell \& Olsson, 1989). Considerando que esse medicamento é de distribuição exclusiva na rede pública de serviços de saúde, o referido sistema poderia ser implantando como um dos componentes dos programas de hanseníase e de DST / Aids, a exemplo do trabalho realizado por Brasil et al. (1996).

Cabe ressaltar a importância do sistema nacional de vigilância de nascimentos vivos, principalmente no seu componente de monitoramento de malformações congênitas. Castilla et al. (1996) detectaram 11 casos de malformações congênitas compatíveis com o uso da talidomida, ocorridas em crianças brasileiras no período de 1971 e 1995, por meio de um sistema de monitoramento de defeitos congênitos implantado em maternidades de dez países da América do Sul.

Os profissionais de saúde constituem um grupo da mais alta relevância para o processo de implementação de uma política de uso racional da talidomida. Os dados relativos às mal- 
formações congênitas atribuídas à talidomida e sua segunda geração de casos são alarmantes, na medida em que evidenciam a falta de informação adequada e a irresponsabilidade gerada pela automedicação. É de estarrecer que, no umbral do Terceiro Milênio, ainda tenhamos a utilização de talidomida em mulheres que se encontravam gestantes no momento da indicação e que não receberam nenhuma orientação no momento da prescrição ou da dispensação.

Nos Estados Unidos, onde a droga foi recentemente aprovada para o uso em hanseníase e onde existem programas de acesso expandido, além de ensaios clínicos em andamento, recomenda-se a adoção de práticas contraceptivas restritivas para todas as pessoas que usam a talidomida (FDA, 1997a). As mulheres são orientadas para usar pelo menos dois métodos, um hormonal e um de barreira, enquanto aos homens, que mantenham relacionamentos sexuais com potencial reprodutivo, é recomendado o uso de camisinha (WHO, 1996; FDA, 1997b; Project Inform, 1997).

Nesse sentido, a promoção do uso racional da talidomida no Brasil implica obrigatoriamente o desenvolvimento de um programa de educação continuada para médicos e farmacêuticos, abordando questões ligadas às boas práticas da prescrição e da dispensação (WHO, 1997).

Concordamos com Lenz (1988) em que qualquer prescrição de medicamento deve ser sempre considerada como um experimento. Isto é particularmente adequado quando falamos da talidomida, pois os conhecimentos dos mecanismos de ação responsáveis por sua eficácia terapêutica e efeitos adversos ainda não estão suficientemente esclarecidos (Calderon et al. 1997). Por isso, achamos pertinente que, no momento da prescrição, seja assinado um documento nos moldes do consentimento livre e esclarecido, conforme regulamentado pela resolução 196/ 96 da Comissão Nacional de Ética em Pesquisa.

As entidades representativas dos grupos sociais envolvidos nas diversas etapas do ciclo de produção e consumo da talidomida têm um papel essencial na garantia da qualidade das informações, assim como no compromisso ético de defesa dos interesses da população (Funtowicz \& Ravetz, 1993; Brown, 1995; Epstein, $1995,1996)$. Atuando em diferentes fóruns oficiais de decisão, desenvolvendo trabal hos comunitários de conscientização pela informação (empowerment) ou na pesquisa de campo, como foi o caso da busca ativa de casos da segunda geração de portadores da síndrome da talidomida, movimentos sociais como a ABPST e o Morhan contribuem efetivamente para os processos de elaboração, implantação e vigilância das políticas de saúde em nosso país.

Dentre os aspectos relevantes para a implantação de políticas de regulação e uso racional de medicamentos no Brasil, estão os interesses econômicos da indústria farmacêutica. Nesse sentido é importante estar atento para o que Abraham (1995) denomina de viés, determinado pela defesa dos interesses das empresas sobre as evidências científicas e os interesses da população. A primeira parte desse trabalho fornece elementos importantes para uma reflexão sobre os métodos usados por essas corporações para atingir suas metas comerciais.

Mokhiber (1995b) chama a atenção para aspectos relacionados à concepção e percepção social dos crimes empresariais, dentre os quais situa o desastre da talidomida. Nesse sentido, é importante que sejam criados mecanismos jurídicos que possibilitem a responsabilização das empresas produtoras e comercial izadoras de medicamentos, principalmente em países em desenvolvimento como o Brasil. De acordo com Maximino \& Scavasin (1997:205), durante o processo judicial impetrado pelas famílias de 250 adolescentes portadores da síndrome da talidomida contra laboratórios produtores no Brasil, estes "se esquivavam de sua cul pa alegando que tinham autorização governamental para a fabricação," ou que "sempre existiram deficientes, a ciência, para acertar, também comete erros", enfim, uma argumentação que visava diminuir sua responsabilidade diante do ocorrido. Após cerca de dez anos de tramitação, o caso se encerrou da seguinte maneira: as três empresas juntas pagaram como indenização uma quantia em dinheiro, que foi rateada por 121 pessoas, de maneira que o maior valor individual recebido foi o equivalente a dois mil dólares, e apenas para aqueles que demonstraram ter deficiência em grau máximo e dependência total.

Esses valores são irrisórios quando comparados aos 31 milhões de dólares que, em 1967, a Chemie Grunenthal concordou em pagar às crianças afetadas pela talidomida na Alemanha. Na Inglaterra, em 1973, a Distillers foi forçada judicialmente a contribuir com dois miIhões de dólares por ano, durante dez anos, para um fundo encarregado de cuidar das 430 crianças sobreviventes (Mokhiber, 1995a). Por esse motivo, Maximino \& Scavasin (1997:205) afirmam que "no Brasil, al guns crimes são compensadores, pois os val ores obtidos com as vendas do produto pagaram as modestas indeniza- 
ções estipuladas e ainda geraram um lucro fantástico".

Funtovitcz \& Ravetz (1993) propõem um modelo de estratégia para resolução de problemas complexos, que em nossa opinião se aplica à questão da definição e implantação de uma política de regulação e uso racional da talidomida. Esses autores denominam de problemas pós-normais aqueles nos quais tanto as incertezas epistemológicas e éticas dos sistemas, quanto o que se coloca em jogo no processo de tomada de decisão, são considerados de alto nível. Nessas situações, são ineficazes os modelos que se apóiam exclusivamente em dados objetivos e quantitativos, típicos da ciência de laboratório. Ao contrário, os acordos públicos e a participação que deriva essencialmente de compromissos valorativos são

\section{Agradecimentos}

Os autores agradecem aos pesquisadores Elizabeth Moreira Santos e Carlos Machado de Freitas a leitura e as sugestões apresentadas a este artigo.

Trabal ho parcialmente financiado com recursos do Programa de Apoio à Pesquisa Estratégica em Saúde (Papes 2/Fiocruz). decisivos para avaliação dos riscos, bem como para a definição e implementação de políticas. Nesse modelo, por exemplo, são envolvidos como participantes essenciais não apenas os técnicos do sistema oficial de regulação e controle, cientistas e médicos, mas também os legítimos representantes dos potenciais usuários da talidomida (comunidades de pares ampliadas) e dos beneficiários econômicos, no caso os laboratórios produtores. Pode-se dizer que foi adotada uma abordagem democrática deste tipo no processo de elaboração da portaria 160/97. Entretanto, o desafio maior será implantar a regulamentação restritiva, expressa nessa portaria, com um sistema de vigilância e responsabilidades compartilhadas com os diversos atores sociais envolvidos nesse processo.

\section{Referências}

ABPST (Associação Brasileira dos Portadores da Síndrome da Talidomida), 1997. A Associação Brasileira dos Portadores da Síndrome da Talidomida, 10 de dezembro «ttp://members.tripod. com/ -abpstalidomida/ >

ABRAHAM, J., 1995. Partial progress? The development or American and British drug regulation. In: Science, Politics, and the Pharmaceutical Industry (J. Abraham, ed.), pp. 36-87, New York: St. Martin's Press.

BERMUDEZ, J. A., 1995. Indústria Farmacêutica, Estado e Sociedade. São Paulo: Hucitec/Sobravime.

BIRIELL, C. \& OLSSON, S., 1989. O programa de farmacovigilância da OMS. In: Epidemiologia do Medicamento - Princípios Gerais (D. Laporte, G. Tognoni \& S. Rozenfeld, org.), pp. 153-176, São Paulo: Editora Hucitec-Abrasco.

BRAITHWAITE, J., 1984. Corporate Crime in Pharmaceutical Industry. London: Routledge \& Kegan Paul.

BRASIL, M.T. L. R. F.; OPROM OLLA, D. V. A.; MARZLIAK, M. L. C. \& NOGUEIRA, W., 1996. Results of a surveillance system for adverse effects in leprosy's WHO/MDT. International Journal of Leprosy, 64:97-104. 
BROWN, P., 1995. Popular epidemiology, toxic waste and social movements. In: Medicine, Health and Risk: Sociological Approaches (J. Gabe, ed.), pp. 90-112, Oxford: Blackwell Publishers Ltd.

CADERNOS PELA VIDDA, 1997. Talidomida: droga "maldita" é liberada para Aids. Cadernos pela VIDDA, 23:7.

CASTILLA, E. E.; ASHTON-PROLLA, P.; BARREDAMEJIA, E.; BRUNONI, D.; CAVALCANTI, D. P.; CORREA-NETO, J.; DELGADILHO, J. L.; DUTRA, M. G.; FELIX, T.; GIRALDO, A.; JUAREZ, N.; LOPEZ-CAMELO, J. S.; NAZER, J.; ORIOLI, I. M.; PAZ, J. E.; PESSOTO, M. A.; PINA-NETO, J. M.; QUADRELLI, R.; RITTLER, M.; RUEDA, S.; SALTOS, M.; SANCHEZ, O. \& SCHÜLER, L., 1996. Talidomide, a current teratogen in South America. Teratology, 54:273-277.

CALDERON, P.; ANZILOTTI, M . \& PHELPS, R., 1997. Thalidomide in dermatology. New indications for an old drug. International Journal of Dermatology, 36:881-887.

CAPPELLÀ, D. \& LAPORTE, J. R., 1989. Métodos empregados em estudos de utilização de medicamentos. In: Epidemiologia do Medicamento: Princípi os Gerais (J. R. Laporte, G. Tognoni \& S. Rozenfeld, org.), pp. 95-138, São Paulo/Rio de Janeiro: Hucitec/ Abrasco.

CRAWFORD, C. L., 1994. Use of thalidomide in leprosy. Adverse Drug Reactions Toxicology Review, 13:177-192.

D'ARCY, P. F. \& GRIFFIN, J. P., 1994. Thalidomide revisited. Adverse Drug Reaction Toxicology, 13:6576.

EPSTEIN, S., 1995. The construction of lay expertise: Aids activism and the forging of credibility in the reform of clinical trials. Science Technology \& Human Values, 20:408-437.

EPSTEIN, S., 1996. Impure Science - Aids, Activism and the Politics of Knowledge. California/ London: University of California Press Ltd.

FAURE, M.; THIVOLET, J.; GAUCHERAND, M., 1980. Inhibition of PMN leucocytes chemotaxis by thalidomide. Archives of Dermatology Research, 269:275-280.

FDA (Food and Drug Administration), 1997a. FDA Issues Approbable Letter to Celgene for Thalidomide. FDA Talk Paper, 15 september বttp:// www.fda.gov/ ... > file:///a/talfdal.html

FDA (Food and Drug Administration), 1997b. Thalidomide Important Patient Information, 9 december বhttp:// www.fda.gov/cder/news/thalidmide.html>

FUNTOWICZ, S. O. \& RAVETZ, J. R., 1993. Riego global, incertidumbre e ignorância. In: Epistemologia Politica - Ciencia com la Gente (S. O. Funtowicz \& J. R. Ravetz, eds.), pp. 11-42, Buenos Aires: Centro Editor de América Latina.

HELLMAN, K.; DUKE, D. I. \& TUCKER, D. F., 1965. Prolongation of skin homograft survival by thalidomide. British Medical Journal, 2:687-689.

IYER, C. G. S.; LANGUILLON, J.; RAM ANUJAM, K.; TARABINI-CASTELLANI, G.; TERENCIO DE LAS AGUAS, J.; BECHESLLI, L. M.; UEMURA, K.; MARTINEZ DOMINGUES, V. \& SUNDARESAN, T., 1971. WHO-coordinated short-term double-blind trial with thalidomide in the treatment of acute lepra reactions in male lepromatous patients. Bulletin of the World Health Organization, 45: 719-732.

KELSEY, F. O., 1988. Thalidomide update: regulatory aspects. Teratology, 38:221-226.

LENZ, W., 1988. A short history of thalidomide embriopathy. Teratology, 38:203-215.

LOCKWOOD, D. M. J., 1996. The management of Erythema Nodosum Leprosum: current and future options. Leprosy Review, 67:253-259.

MAKONKAWKEYOON, S.; LIMSON-PROBRE, R. N.; MOREIRA AL SCHAUF, V. \& KAPLAN, G., 1993. Thalidomide inhibits replication of human immunodefidiency virus type 1 . Procedures of $\mathrm{Na}$ tional Academy of Science, 90:5.974-5.978.

MAXIMINO, C. M. \& SCAVASIN, F. A., 1997. Trinta e cinco anos de luta. In: Direitos da Pessoa Portadora de Deficiência (G. J. P. de Figueiredo, org.), pp. 203-211, São Paulo: Ed. Max Limonad.

MCBRIDE, W. G., 1961. Thalidomide and congenital abnormalities. Lancet, 2:1.358.

MCLEAN, B., 1997. O regresso de um remédio maldito: talidomida, segunda parte. Jornal do Brasil, Rio de Janeiro, 30 de setembro, Caderno Especial Fortune Americas, p. 4.

MELLIN, G. W. \& KATZENSTEIN, M., 1962a. The saga or thalidomide: neuropathy to embriopathy, with case reports of congenital anomalies. New England Journal of Medicine, 6:1.184-1.192.

MELLIN, G. W. \& KATZENSTEIN, M., 1962b. The saga or thalidomide (concluded): neuropathy to embriopathy, with case reports of congenital anomalies. New Engl and Journal of Medicine, 6:1.2381.243.

MOKHIBER, R., 1995a. Talidomida. In: Crimes Corporativos: O Poder das Grandes Empresas e o Abuso da Confiança Pública (R. Mokhiber, org.), pp. 369-376, São Paulo: Ed. Página Aberta.

MOKHIBER, R., 1995b. Crime e violência empresarial. In: Crimes Corporativos: O Poder das Grandes Empresas e o Abuso da Confiança Pública (R. Mokhiber, org.), pp. 11-69, São Paulo: Ed. Página Aberta.

MOREIRA, A. L.; SAM PAIO, E. P.; ZMUIDZINAS, A.; FRINDT, P.; SMITH, K. A. \& KAPLAN G., 1993. Thalidomide exerts its inhibitory action on tumor necrosis factor al pha by enhancing mRNA degradation. Journal of Experimental Medicine, 177: 1.675-1.680.

MOREIRA, A. L.; CORRAL, L. G.; YE, W.; JOHNSON, B.; STIRLING, D.; GEORGE, W. M.; FEEDMAN, V. H. \& KAPLAN, G., 1997. Thalidomide and thalidomide analogs reduce HIV Type 1 replication in human macrophages in vitro. Aids Research and Human Retroviruses, 10:857-863.

PROENÇA, N., 1995. Emprego de talidomida em dermatologia. Anais Brasileiros de Dermatologia, 70: 61-67.

PROJECT INFORM, 1996a. Thalidomide Fact Sheet Packet, 10 october বhttp:// www.projinf.org/fs/ thalido.html>

PROJECT INFORM, 1996b. Thalidomide Addenda, 16 july বhttp:// www.projinf.org/addenda/ thalidomide.html>

PROJECT INFORM, 1997. Thalidomide Quick Sheet, 10 october \&http://www.projinf.org/cgi-bin/ 
print_hit_...pl/qs/thalidomide.html/thalidomide\#first_hit>

PWA (People with Aids) Health Group, 1995. Taking Thalidomide for HIV-Related Oral Ulcers and Weight Loss. A Guidebook for People with Aids, 22 july বhttp:// www.aidsnyc.org/ pwahg/info/ thal. html \#work>

REYES-TERAN, G.; SIERRA-MADERO, J. G.; MARTINEZ DEL CERRO,V.; ARROYO-FIGUEROA, H.; PASQUETTI, A.; CALVA, J. J. \& RUIZ-PALACIOS, G., 1996. Effects of thalidomide on HIV-associated wasting syndrome: a randomized, doubleblind, placebo-controlled clinical trial. Aids, 10: 151-157.

RUTTER, T., 1997. Thalidomide ban to be lift in the US. British Medical Journal, 315:697-702.

SAMPAIO, E. P.; SARNO, E. N.; GALILLY, R., COHN, Z. A. \& KAPLAN, G., 1991. Thalidomide selectively inhibits tumor necrosis factor al pha production by stimulated human monocytes. Journal of Experimental Medicine, 173:699-703.

SAM PAIO, E. P.; KAPLAN, G.; MIRANDA, A.; NERY, J. A. C.; MIGUEL, C. P.; VIANA, S. M. \& SARNO, E., 1993. The influence of thalidomide on clinical and immunologic manifestation of Erythema Nodosum Leprosum. Journal of Infectious Diseases, 168:408-414.

SCHWARTZ, H., 1997. Cost vs benefit in the rebirth of thalidomide - the Schwartz view. Scrip Magazine, november:30-31.

SHESKIN, J., 1965a. Thalidomide in lepra reactions. Clinical Pharmacology Therapy, 6:303-306.

SHESKIN, J., 1965b. Further observations with thalidomide in lepra reactions. Leprosy Review, 36:183185.
SHESKIN, J. \& SAGHER, F., 1975. World survey on the use of thalidomide in leprosy reaction. Medical Cutaneo I bero Latin America, 3:81-83.

STIRLING, D.; SHERMAN, M. \& STRAUSS, S., 1997. Thalidomide a surprising recovery. Journal of American Pharmaceutical Association, NS37:307313.

TSENG, S.; PAK, G.; WASHENIK, K.; POMERANZ, M K. \& SHUPACK, J. L., 1996. Rediscovering thalidomide: a review of its mechanism of action, side effects and potencial uses. Journal of the American Academy of Dermatology, 35:969-979.

VOGELSANG, G. B.; FARMER, E. R.; HESS, A. D.; ALTAM ONTE, V.; BESCHORNER, W. E.; JABS, D. A.; CORIO, R. L.; LEVIN, L. S.; COLVEIN, O. M.; WINGARD, J. R. \& SANTOS, G. W., 1992. Thalidomide for treatment of chronic graft-versus-host disease. New England Journal of Medicine, 326: 1.055-1.058.

WHO (World Health Organization), 1988. Expert Committee on Leprosy. Sixth Report of WHO Expert Committee, WHO Technical Report Series 768. Geneve: WHO.

WHO (World Health Organization), 1996. Thalidomide- Usein Aids in the United States of America. WHO Pharmaceuticals Newsletter 8. Geneve: WHO.

WHO (World Health Organization), 1997. Public-Private Roles in the Pharmaceutical Sector - Implications for Equitable Access and Racional Drug Use. Health Economics and Drugs DAP Series 5. Geneve: WHO.

ZWINGENBERGER, K. \& WNENDT, S., 1996. Immunomodulation by thalidomide: systematic review of the literature and unpublished observations. Journal of Inflamation, 46:177-211. 